\title{
Desafio conceitual e metodológico para o estudo dos sistemas de gênero no desenvolvimento territorial
}

\author{
Resenha escrita por Walterlina Brasil \\ ${ }^{a}$ Universidade Federal de Rondônia, UNIR, \\ Porto Velho, RO, Brasil \\ E-mail:gepes@unir.br
}

doi:10.18472/SustDeb.v7n2.2016.19819

\begin{abstract}
Susan Paulson. Masculinidades en movimiento: Transformación territorial y sistemas de género. Buenos Aires: Teseo, 2013. 252 p. ISBN 978-987-1867-69-1. Disponível gratuitamente online: http:// www.rimisp.org/wp-content/files_mf/13838550419789871867691ebook.pdf.
\end{abstract}

Masculinidades em Movimiento é o sétimo livro nos campos de gênero e ecologia política de autoria de Susan Paulson, antropóloga e professora no Center for Latin American Studies na University of Florida. Como as suas obras anteriores, resulta de uma vasta rede de colaborações. O livro tem as suas raízes em dois conjuntos de pesquisas: (i) um grande estudo comparativo sobre dinâmicas de territórios rurais (DTR) em 20 territórios rurais dentro de 11 países de América Latina (financiado pelo International Development Research Centre, do Canadá, e coordenado pelo Centro Latinoamericano para el Desarrollo Rural - Rimisp) e (ii) as dissertações de dez alunos de dois mestrados interdisciplinares -- Cultura, Poder e Sustentabilidade, e Práticas em Desenvolvimento Sustentável -- na Universidade de Lund, na Suécia.

O estudo sobre DTR gerou dados comparativos e longitudinais, mas não houve um foco em gênero; as dez dissertações são estudos menores e complementares que focaram em aspectos de gênero em alguns dos mesmos territórios. Portanto, três dos nove capítulos têm co-autoria desses mestrandos: Teresa Bornschlegl (no caso de Chile), Bruno Portillo Seminario (Equador) e Carina Emanuelsson e Maritza Florian, em co-autoria também com a pesquisadora do Rimisp, Ana Victoria Peláez (Guatemala).

Com base nesse conjunto de pesquisas, a obra integra questões de desenvolvimento rural e gênero, apresentando análises que relacionem mudanças ocorridas no uso do território, novos modelos de desenvolvimento econômico e a distribuição do trabalho entre homens e mulheres. Explora a relação entre as ditas "diferenças" de gênero e o resultado econômico conforme constatados em diferentes setores produtivos, tratados como estudos de caso. A análise sistêmica permitiu aprofundar questões relativas ao gênero e ao seu papel opressor de modo independente da subordinação baseada em classe ou raça.

A discussão está ambientada em observações desde a década de 1980 que a América Latina tem crescido economicamente, mas que este resultado macro não trouxe a superação das desigualdades sociais nem da distinção entre as atividades de homens e mulheres. Os autores basearam os seus estudos em metodologias que fazem um cruzamento entre gênero e desenvolvimento territorial rural, sustentando que essa abordagem auxilia na compreensão da diferenciação entre homens e mulheres que, por sua vez, atravessa toda dinâmica rural. 
Uma análise mais rigorosa dos papeis femininos e masculinos depende do método de pesquisa adotado. Apostando em um formato integral e na interdisciplinaridade da equipe de autores vinculados à pesquisa, os primeiros três capítulos apresentam a base teórica e metodológica. Fornecem a visão geral dos fundamentos do estudo sobre a capacidade de os grupos interagirem e de estabelecerem relações flexíveis ou de retorno adaptativo às situações que julgam desejáveis para a transformação produtiva na América Latina. Neste aspecto, apresenta-se o conceito básico para estudos sobre gênero de "sistemas de gênero" (Capítulo 3), que aborda as assimetrias de papeis e recursos entre homens e mulheres e como estas interagem com história, instituições e geografia para gerar impactos em renda, distribuição de recursos e mudanças ambientais. Um avanço conceitual importante na obra é superar o enfoque tradicional em estudos de gênero de limitar a análise à percepção da condição da mulher, introduzindo a percepção de que as masculinidades também dizem respeito à dinâmica rural e estão em movimento.

No caso sobre a indústria de salmão na ilha de Chiloé em Chile (Capítulo 4, p.103), a definição do trabalho se deu em razão dos dois estereótipos sobre as habilidades distintas e "naturais" para as tarefas de homens (duros) e de mulheres (minuciosas). Entretanto, nenhum dos grupos se beneficia dos estereótipos em torno da remuneração. No Equador, dois estudos de caso em Loja (Capítulo 6, p. 145) analisam a tecnificação da produção de milho que, sendo uma decisão masculina, praticamente marginalizou as mulheres, enquanto que o plantio do café orgânico e o ingresso no esquema do comércio justo, em outro território, acabou por integrar homens e mulheres. O capítulo contrasta, portanto, modelos individualísticos e colaborativos de masculinidade.

O caso em Ostua-Quija (Guatemala, Capítulo 8, p. 187) analisa a agroindústria de tomate, em ascensão, e a produção de calçados, em declínio. Documenta a invisibilidade de um conjunto de atividades produtivas que contribuem para o desenvolvimento territorial desempenhadas por um grande número de mulheres, além de crianças e homens. O capítulo levanta vieses embutidas nas práticas de pesquisa e as representações culturais que reforçam esse tipo de invisibilidade.

O foco do Capítulo 7 (p. 171) recai justamente sobre os pressupostos e práticas de pesquisa que limitam a percepção de aspectos relevantes para o estudo acadêmico de gênero. Usando interpretações comuns do Gender Gap Index, o capítulo mostra que, embora os homens sejam favorecidos em alguns variáveis e mulheres sejam favorecidas em outros, a interpretação dominante e o próprio índice consideram apenas os itens nos quais as mulheres ficam para trás.

O livro como um todo propugna pelo investimento em teorias e metodologias que permitam desvendar masculinidades mais colaborativas, visando uma percepção mais adequada sobre o estudo das diferenças e desigualdades entre homens e mulheres como inibidores da compreensão do ambiente rural.

A variedade dos estudos de caso e a busca de um método de pesquisa que equilibre masculinidades e feminilidades permitem discutir as relações de diversas naturezas envolvendo o vínculo homem-muIher e todos os vínculos sociais decorrentes das diversidades de atores. Questões ideológicas também são resgatadas nas análises dos estudos de caso. É possível notar que as relações, interações, sistemas complexos e diversos produzem perspectivas sobre as mudanças socioeconômicas e ecológicas, decorrentes da forte capacidade de adaptação que estes grupos e as suas circunstâncias produzem mutuamente. A perspectiva teórica é o ponto forte a ser destacado no livro. Dentro de uma abordagem sistêmica transita sobre os aspectos em que há uma conexão com sentidos, significados e práticas sociológicas e no quanto o tema do gênero se apresenta nas relações humanas, influindo no desenvolvimento institucional e nas expressões de espaço, tempo e cultura.

Dentro de tamanha complexidade, o livro reconhece que o gênero funciona "como um sistema semiótico" (p. 90) em que diversos elementos estão conectados. Assim, os estudos de caso permitem questionar quais elementos podem ser identificados na relação entre gênero e território. A obra contribui para estudos relacionados à resiliência socioecológica, por integrar à discussão da dimensão social e ecológica a compreensão das contradições internas do próprio sistema. 